\title{
Inflammation is a Basis for Most of All Diseases
}

\author{
Shrihari TG* \\ Department of Oral Medicine and Oral Oncology, India \\ *Corresponding author: Shrihari TG, Department of Oral Medicine and Oral Oncology, India
}

Submission: 眥June 02, 2018; Published: 眥 January 25, 2019

\begin{abstract}
inflammation is the body's defensive action against noxious stimuli. If the inflammation is aggravated chronically by various agents such as chronic psychological stress, chemical agents, infectious agents, physical injury results in release of various inflammatory mediators such as cytokines, chemokine's, growth factors from inflammatory cells activate key transcription factors such as NF-KB and STAT-3, results in tissue damage, immune modulation, and cellular changes involved in many diseases such as auto-immune disease, cancer, diabetes, Alzheimer's disease, heart disease. Hence, chronic inflammation is considered as a basis for almost all diseases. This article briefs about the role of chronic inflammation in pathogenesis of various diseases.
\end{abstract}

Keywords: Cancer; Auto-immune disease; Diabetes; NK-KB; STAT-3; Alzheimer’s disease; Heart disease; IL-1; TNF- $\alpha$; IL-6

\section{Introduction}

Inflammation is the body's defensive action against noxious stimuli such as physical or chemical or thermal injury. During the process of acute inflammation, various inflammatory mediators are released such as chemokine's, cytokines, growth factors, enzymes, are released from inflammatory cells to heal and regenerate the injured tissue. If the inflammation is aggravated chronically, smoldering inflammation results in dysregulated immune cells, causes tissue damage by activating transcription factors such as NF-KB, STAT-3 and leads to various diseases such as auto-immune diseases, cancer, infectious diseases, heart diseases and diabetes [1-13].

\section{Role of inflammation in pathogenesis of various diseases}

Chronic inflammation is a basis for most of all diseases. $90 \%$ of most of all cancers are due to external environmental factors such as tobacco, alcohol, chemical ingestion, dietary factors, infectious agents (HPV, EBV), leading to various cancers such as oral cancer, lung cancer, gastro-intestinal cancer, oro-pharyngeal cancer, cervical and breast cancer. Chronic inflammation leading to production of inflammatory mediators, such as cytokines (IL-1, TNF- $\alpha$, IL-6, IL-8, IL-10), chemokines are chemotactic cytokines that involve in positioning and migrating patterns of immune cells to the site of inflammation. Chemokines helps in recruitment of neutrophils by CXCL-1, CXCL-2, CXCL-3, CXCL-5, CXCL-6, CXC7, CXCL-8. Recruitment of macrophages, dendritic cells and natural killer cells are by chemokines, CCL-2, CXCL12- CXCR4. CCL-4, CCL-5, and MCP-1. Recruitment of lymphocytes and natural killer cells by chemokines CXCL-12, CXCR-4, CXCL-9, CXCL-10, CXCL-11, CCR-7, CCL-21, CXCL-
19, CCL-12. TNF- $\alpha$, IL-1 and COX-2 activate NK-KB a key transcription factor and TNF- $\alpha$ activate AP-1 transcription factor, IL-6, EGF, IL-10, 1L-22, 1L-11, HGF activates STAT-3 transcription factor. HIF-I $\alpha$ in hypoxic tumor micro environment produced by macrophages acts as a transcription factor for COX-2, IL-8, VEGF involved in angiogenesis. Chronic inflammation is considered as a 7th hallmark of cancer. Receptors of chemokine's are expressed on leukocytes produced by stromal and tumor cells facilitates tumor progression. Growth factors (EGF, FGF, VEGF) produced by tumor associated macrophages, tumor associated neutrophils, mast cells activate transcription factors (NF-KB, STAT-3) involved in cell proliferation (cycline-d, C-MYC, P21), cell survival (bcl-2, BCLXL, C-FLIP, SURVIVIN, IAP1/2, TRAF 1/2). Angiogenesis (COX-2, HIF1- $\alpha$, IL-8, VEGF), immune response and chronic inflammation (MHC-1, cytokines, MHC-2), immune suppression (TGF- $\beta$, T-regs, B-regs, IL-10, i-NOS), genomic instability (ROS, RNS, AID), invasion and metastasis (ICAM-1, VCAM-1, E-Selectin, UPA, fibronectin, TGF- $\beta$, MMP-2,9 and ELAM-1) [7-10]. Chronic psychological Stress induced inflammatory mediators are cytokines, IL-1, IL-6, TNF- $\alpha$, activate NF-KB transcription factor causes destruction of pancreatic cells of Langerhans leads to diabetes [1-3]. Chronic psychological stress mediated activation of corticotrophin releasing hormone (CRH), from hypothalamus activate HPA- axis (Hypothalamo pituitary adrenal axis) through sympathetic nervous system of ANS (Autonomic nervous system) release nor-adrenaline, ACTH and cortisol, activate inflammatory mediators, such as IL-1, TNF- $\alpha$, IL6, COX-2, Which activates NF-KB and STAT-3 transcription factors involved in chronic inflammation, tumor progression, autoimmune 
diseases, infectious diseases. NF-KB a key transcription factor induced inflammatory mediators involved in conversion of TH1 to TH2 lymphocytic type, release IL-4,IL-5,IL-13 invoved in chronic inflammation, tissue damage, and immunemodulation. Altered induced regulatory T-cells( iTregs) formed from TH1 cells mediated by TGF- $\beta$ inflammatory mediator, release IL-3,IL-4,IL5,IL-10,IL-13,IL-17 pro-inflammatory cytokines involved in tissue damage, immunemodulation, otherwise normal regulatory $\mathrm{T}$ cells (nTregs) involved in self- tolerance and immune homeostasis, these immunological and cellular changes leads to auto-immune disease [13-16].

Inflammatory mediators such as IL-1, TNF- $\alpha$, IL-6, and free radicals (ROS, RNS) induced by tobacco consumption in the form of smoking, and chewable form, alcohol, psychological stress causes damage to the tunica intima of coronary blood vessels and endothelial lining cells leads to formation of plaque results in obstruction of blood flow later results in ischemia and heart failure [2-12]. Alzheimer's disease is mainly due to inflammatory mediators such as IL-1, TNF- $\alpha$, IL-6 from inflammatory cells such as neutrophils, macrophages, mast cells induced reactive oxygen species, causes tissue damage and cellular changes results in deposition of amyloid by microglial cells of central nervous system which is a main cause for memory loss in Alzheimer's patients [4-6]. Infectious diseases such as bacterial and viral infections cause release of inflammatory mediators, such as IL-1, TNF- $\alpha$, IL- 6 pro-inflammatory cytokines are responsible for fever and other prodromal symptoms. In infectious disease, the infectious agents such as microbes and microbial products are recognized by PAMP (pathogen associated molecular patterns) belongs to pattern recognition receptors of toll like receptors, cytokines activates key transcription factors such as NF-KB, STAT-3, involved in chronic inflammation, immune modulation, cell survival, tissue damage, autoimmune diseases, cancer progression, results in various clinical signs and symptoms of disease [9-11].

\section{Conclusion}

Acute inflammation is a defensive mechanism against any type of injury. If the inflammation is aggravated chronically, chronic inflammation results in offensive action involved in tissue damage, immunemodulation, and chronic inflammation leads to various diseases. Thorough understanding of the disease, causative agents, and chronic inflammation related pathogenesis is helpful for future therapeutic purpose.

\section{References}

1. Esser N, Legrand poles S, Piette J, Scheen AJ, Paquot N (2014) Inflammation as a link between obesity, metabolic syndrome and type 2 diabetes. Diabetes Res Clin Pract 105(2): 141-50.

2. Alberti KG, Eckel RH, Grundy SM, Zimmet PZ, Cleeman JI, Donatoka KA (2014) Harmonizing the metabolic syndrome: a joint interim statement of the international diabetes federation task force on epidemiology and prevention; National heart, lung and blood institute; American heart association, world heart federation; International atherosclerosis society; and international association for the study of obesity. circulation 120(16): 1640-1645

3. Gregor MF, Hotamisligil GS (2015) Inflammatory mechanisms in obesity Annual Review of Immunology 29: 415-445.

4. Patrick L, Geer MC, G Edith (2017) The amyloid cascade-inflammatory hypothesis of Alzheimer disease. ADAPT Research group 2006 cardiovascular and cerebrovascular events in the randomized, controlled Alzheimer's disease anti-inflammatory prevention trial PLOS.

5. Malu G, Tansey, Amarallys F, Cintron, Athryn P, et al. (2017) Elevated central and peripheral inflammatory profiles in a population at risk for Alzheimer's disease. The journal of the alzheimer's association 07: 231.

6. Shoghijadid K, Small GW, Agdeppa ED, Kepe V, Ercoli LM, et al. (2018) Localization of neurofibrillary tangles and beta amyloid plaques in the brains of living patients with Alzheimer disease. AM I Geriatric Psychiatry 10(1): 24-35.

7. Singh-Manoux A, Shipley MJ, Bell JA, Canonico M, Elbaz A, et al. (2017) Association between inflammatory biomarkers and all-cause, cardiovascular and cancer related mortality. CMAJ 189(10): E384-E390.

8. Shrihari TG (2017) Dual role of inflammatory mediators in cancer Ecancermedicalscience 11: 721-730.

9. Grivennikov SI, Greten FR, Karin M (2010) Immunity, inflammation, cancer. Cell 140(6): 883-899.

10. Landskron G, De la Fuente $\mathrm{M}$, Thuwajit $\mathrm{P}$, Thuwajit $\mathrm{CH}$, Hermoso MA (2014) Chronic inflammation and cytokines in the tumor micro environment. Journal of Immunology Research 2014(2014): 1-19.

11. Shrihari TG (2012) Potential co-relation between chronic periodontitis and coronary artery diseases. General dentistry 5: 1-12.

12. Lopez-Candales A, Hernández Burgos PM, Hernandez-Suarez DF, Harris D (2017) Linking chronic inflammation with cardiovascular disease: From normal aging to the metabolic syndrome. J Natl Science 3(4): e341.

13. Stojanovich L (2010) Stress and autoimmunity. Autoimmunity reviews 9(5): 271-276.

14. Stojanovich L, Marisavijevich D (2008) Stress as a trigger of autoimmune disease. Autoimmun Rev 7(3): 209-213.

15. Shrihari TG (2018) Current concept of Auto-immune disease and holistic therapeutic approach. EC microbiology15(2): 103-107.

16. Shrihari TG (2018) Beta-Endorphins-Therapeutic Boon. International Journal of Modern Pharmaceutical Research 2(6):7-8. 
Creative Commons Attribution 4.0 International License

For possible submissions Click Here
Submit Article

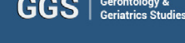

\section{Gerontology \& Geriatrics Studies}

Benefits of Publishing with us

- High-level peer review and editorial services

- Freely accessible online immediately upon publication

- Authors retain the copyright to their work

- Licensing it under a Creative Commons license

- Visibility through different online platforms 